\title{
Bioassay evaluation of toxicity reduction in common effluent treatment plant
}

\author{
V. K. Tyagi ${ }^{*}$, A. K. Chopra ${ }^{2}$, N. C. Durgapal ${ }^{3}$ and A. A. Kazmi ${ }^{1}$ \\ ${ }^{1}$ Department of Civil Engineering, Indian Institute of Technology, Roorkee - 247667, INDIA \\ ${ }^{2}$ Department of Zoology and Environmental Science, Gurukula Kangri University, Haridwar-249404, INDIA \\ ${ }^{3}$ Central Pollution Control Board, Delhi - 110 032, INDIA \\ *Corresponding author. E-mail: vinayiitr@ rediffmail.com
}

\begin{abstract}
This paper investigates the utility and validity of bioassay toxicity testing using Daphnia magna straus as test organism for monitoring the common effluent treatment plant (CETP) receiving both industrial as well as domestic effluent. The average daphnia toxicity (Gd) at inlet, after primary settling tank (PST), secondary settling tank (SST) and tertiary treatment unit were reported as $\mathrm{Gd}-16, \mathrm{Gd}-12, \mathrm{Gd}-4$ and $\mathrm{Gd}-1$ respectively. However, a cumulative percentage removal in toxicity after PST, SST and tertiary treatment units was observed as $25 \%, 75 \%$ and $100 \%$, respectively, during entire study period. It showed that a complete removal in daphnia toxicity $(\mathrm{Gd})$ i.e. $100 \%$ had been achieved only after tertiary treatment unit involving Dual Media Filters followed by activated carbon filters. Further attempts have been made to establish the relationship between key wastewater constituents i.e. Chemical Oxygen Demand (COD) and Suspended Solids (SS) with respects to daphnia toxicity (Gd). It was observed that COD and SS show a statistically significant correlation $\left(r^{2}\right)$ with daphnia toxicity $(\mathrm{Gd})$ i.e. 0.89 and 0.81 , respectively. Thus COD and SS can serve as a regulatory tool in lieu of an explicit toxicity standard (to check and improve the operational status of wastewater treatment plants in time).
\end{abstract}

Keywords: Toxicity, CETP, Daphnia magna straus

\section{INTRODUCTION}

Water pollution has become a major threat to the existence of living organisms in aquatic environment. A huge quantity of pollutants in the form of domestic and industrial effluents is discharged directly or indirectly into the water bodies, which has severe impacts on its biotic and abiotic environment (Turk and Turk, 1984).

The standard quality of waste effluents has traditionally been based on the control of global parameters such as biochemical oxygen demand (BOD), Chemical Oxygen Demand (COD) or Total Suspended Solids (TSS) according to the waste water treatment directive 91/271/EEC. The detection of these parameters alone is not sufficient, as the waste water generated from small scale industries may contains large amount of chemicals, many of which may be present in such a low concentrations that these may be beyond detection limit and for many of them even the analytical techniques are inadequate. Secondly, the physico-chemical analysis is not only quite complicated, expensive and time consuming process, but also lacks the information about the additive, antagonistic or synergistic effects of various chemicals on biotic community in aquatic ecosystem (Villegas -Navarro etal., 1999). Therefore, effective tools for the evaluation of negative effects of waste effluent on living organisms are needed. The toxicity test is one of such parameters, which covers all above shortcomings and can be used as summary parameters (easier, cheaper, effective and less time consuming). The measure of toxicity is an integral view of the sum of all interacting components in the sample. The purpose of regulatory toxicity testing is to produce baseline data for environmental hazard and risk assessment of chemicals, to be used in regulating the discharge of wastewater treatment systems. Bioassay has been extensively used to document toxicity of surface water and evaluate the potential toxicity of discharges into these waters (Blinova, 2000). Numerous studies have been made to understand the toxic effects of waste effluents on fish, but relatively little attention has been paid to their adverse effects on plankton. In view of the importance of cladocerons as an important link in the food chain in aquatic ecosystem, the present work was carried out upon the toxic effects of waste effluents on Daphnia magna straus. Which is highly sensitive to toxic substances, has short generation time, multiplies very rapidly, easily acclimatizes in laboratory condition, cultured in a small space and can be measured in a relatively short period (APHA, 1998 and German Standard Method, 1989). Earlier studies revealed that Daphnia magna could be used as a sensitive indicator for effluent 
toxicity measurement (Verma et al., 2003).

The acceptance of bioassay toxicity test as an effective analytical tool requires guarantees of standardization and validation of the experimental procedure to evaluate its sensitivity, accuracy or precision. In this sense, the main objectives of this work was to assess the utility of toxicity tests and to apply the bioassay toxicity testing for monitoring of wastewater treatment plants.

\section{MATERIALS AND METHODS}

Site study : Toxicity evaluation study was carried out at the CETP, located at Mangolpuri industrial area, Phase I, West Delhi Segment. The designed treatment capacity of the plant is $2400 \mathrm{~m}^{3} / \mathrm{d}(2.4 \mathrm{MLD})$ and it receives the waste effluent from 570 industrial units includes rubber, food processing, dying, plastic, and electroplating industries.

The treatment system consist of primary treatment with screens, grit chamber, equalization tank, primary clarifier followed by secondary treatment with complete mix activated sludge process, secondary clarifier and tertiary treatment units involving dual media filter (sand filter) and activated carbon filters. Sludge handling facilities consists of gravity thickener, sludge digester and sludge drying beds.

Sampling : Wastewater samples were drawn from receiving chamber (raw wastewater), after primary and secondary clarifier and clean water sump (finally treated effluent). Composite sampling was adopted as per standard method (APHA, 1998), to avoid possibly daily variation in the composition of flow. Wastewater samples for toxicological analysis were collected in non- reactive sterilized borosilicate glass bottles of $500 \mathrm{ml}$ capacity. The sample were transported in an ice box to Bio- Science laboratory of Central Pollution Control Board, Delhi and stored at a temperature of $4^{\circ} \mathrm{C}$ to avoid deterioration. The toxicity test was carried out within next $24 \mathrm{hr}$.

Sampling Analysis : Bioassay test using Daphnia magna were conducted following the German Standard Method (1989), METHOD DIN 38412- L30. COD was defined as the amount of oxygen consumed in the sample during it's chemically digestion over $2 \mathrm{hrs}$ at $150^{\circ} \mathrm{C}$. (APHA, 1998). Data were expressed in $\mathrm{mg} \mathrm{O}_{2} /$ l. Suspended Solids (SS) were estimated as the weight of solids material retained on pre-weighted Whatman filter paper after filtering a known volume of sample and drying the filter / membrane at $105^{\circ} \mathrm{C}$ until a constant weight was reached. Data were expressed in $\mathrm{mg} / \mathrm{l}$. The wastewater samples collected from the various treatment units of CETP were analyzed for weekly/ monthly variations from December 2001- March 2002.

Daphnia magna used in the experiment were selected from the laboratory stock culture, maintained at $24 \pm 1^{\circ} \mathrm{C}$ in 2 lit. glass beaker and were fed on green algaScendesmus substpicatus. 24 hours prior to the test adult Daphnia magna were stored and the young one (neonates) produced from these adults were used in experiments. Dilution water was prepared by using $25 \mathrm{ml}$ of each stock solution i.e.

$\mathrm{KCl}$ (Potassium chloride)

$\mathrm{CaCl}_{2} \cdot 2 \mathrm{H}_{2} \mathrm{O}$ (Calcium chloride solution)

$\mathrm{NaHCO}_{3}$ (Sodium bicarbonate solutions) and

$\mathrm{MgSO}_{4} .7 \mathrm{H}_{2} \mathrm{O}$ (Magnesium sulphate solution)

in per liter of double distilled water.

Procedure : The neonates of $1 \mathrm{~mm}$ was collected for the toxicity test by separating the old Daphnids with a nylon sieve plate with a mesh of approximately $1 \mathrm{~mm} \times 1 \mathrm{~mm}$. Daphnids were exposed to different concentration of dilution series (i.e. 1, 2, 3, 4, 6, 8, 12, 16, 24, 32 ....) prepared according to German standard method (1989). Five numbers of Daphnids per $20 \mathrm{ml}$ of test solution was taken in $50 \mathrm{ml}$ glass beaker. Tests were run in duplicate. A control set containing dilution water was also run simultaneously. Test was carried out in two phase i.e. Range Finding Test (RFT) and Standard Test. Observation was made for dead or immobilized Daphnids after $24 \mathrm{hrs}$ to $48 \mathrm{hrs}$ of exposure. On the basis of Daphnia magna mortality up to 5 consecutive concentrations have to be selected from RFT dilutions for standard test. The standard test is a confirmatory test, performed to determine Gd value, which is the smallest value of dilution for Test solution in which all Daphnia magna remain capable of swimming. The lowest value of $\mathrm{G}$ (Gd value) was reported for the Test liquid in which at least 4 Daphnia magna have retained their swimming ability and indicate dilution factor $(\mathrm{Gd})$ as test result. In case of more than 1 mortality in check liquid/ control set the experiment was discarded and repeated again.

\section{RESULTS AND DISCUSSION}

Toxicity removal efficiency of CETP : Table 1 gives the descriptive data (average) on sampling frequency, Daphnia magna toxicity (Gd), COD and SS concentration at different treatment levels and the overall plant efficiency w.r.t. to percentage removal of abovementioned parameters.

The variations in Gd, COD and SS concentrations are also illustrated graphically in fig.1, 2 and 3 . The mean influent toxicity was Gd- 16 . Toxicity after primary, secondary and tertiary treatment units was found to be Gd8-Gd12, Gd3- Gd4 and Gd1, respectively. The toxicity of wastewater is reduced cumulatively from influent to effluent. The mean percentage removal in toxicity after primary, secondary and tertiary treatment units were found to be $29 \%, 76 \%$ and $100 \%$, respectively. It shows that treatment of wastewater up to secondary level is not 
Table 1. Summary of test protocol for Daphniamagna bioassay.

\begin{tabular}{|c|c|c|}
\hline S.No. & Test Type & Static \\
\hline 1. & Temperature & $24 \pm 1^{0} \mathrm{C}$ \\
\hline 2. & Light & Ambient laboratory illumination \\
\hline 3. & Test vessel & $50 \mathrm{ml}$ glass beaker \\
\hline 4. & $\begin{array}{l}\text { Test solution } \\
\text { volume }\end{array}$ & $20 \mathrm{ml}$ \\
\hline 5. & $\begin{array}{c}\text { Test organisms/ } \\
\text { vessel }\end{array}$ & 5 \\
\hline 6. & Replicate & 2 \\
\hline 7. & Test concentration & $1,2,3,4,6,8,12,16,24,32$ \\
\hline 8. & Feeding regime & No feeding during exposure \\
\hline 9. & Control water & Standard dilution water \\
\hline 10. & Test duration & $24 \mathrm{hrs}$ to $48 \mathrm{hrs}$ \\
\hline 11. & End point & Immobilization / death \\
\hline
\end{tabular}

satisfactory itself to reduce wastewater toxicity completely or its maximum extent. We found the $100 \%$ removal in Daphnia toxicity (Gd) only after tertiary treatment of wastewater. The use of Daphnia magna in toxicology is accepted in several countries to monitor wastewater treatment systems, establish quality criteria to determine permissible concentrations of pollutants, limits of impurity in water from natural effluents, as well as to determine the efficacy of a good sanitation method (Villegas- Navarro et al., 1999).

The mean influent COD and SS were found in the ranges of $349 \mathrm{mg} / \mathrm{l}$ and $160 \mathrm{mg} / \mathrm{l}$, respectively. After primary, secondary and tertiary treatment both COD and SS were observed within a mean range of $254 \mathrm{mg} / \mathrm{l}, 150 \mathrm{mg} / \mathrm{l}, 123$ $\mathrm{mg} / \mathrm{l}$ and $146 \mathrm{mg} / \mathrm{l}, 110 \mathrm{mg} / \mathrm{l}$ and $26 \mathrm{mg} / \mathrm{l}$, respectively. The findings revealed that a systematic removal in COD and SS concentration founds from influent to effluent. The mean percentage removal in COD and SS after primary, secondary and tertiary treatment level had been found to be $27 \%, 57 \%, 65 \%$ and $10 \%, 31 \%$ and $84 \%$ respectively.

Thus the observations discloses that COD, SS and Daphnia toxicity $(\mathrm{Gd})$ reduce slightly at primary treatment level and significantly at secondary treatment level, while as the optimal and maximum removal in Gd, COD and SS concentration were found at tertiary treatment level. Figure 4 shows the cumulative percentage reduction of performance parameters at different treatment levels of CETP.

Interrelationship between Daphnia toxicity (Gd), COD and SS : On the basis of data obtained we tried to establish relationship between two key wastewater constituents i.e. COD and SS with Daphnia toxicity (Gd). From the plots of fig. 4 and 5 the following relationships were obtained between key parameters,

$\mathrm{Gd}=0.0631 \mathrm{COD}-5.9436\left(\mathrm{r}^{2}=0.899\right)$.

Table 2. Descriptive data and removal efficiency of performance parameters at CETP.

\begin{tabular}{|c|c|c|c|c|c|c|c|c|c|c|c|c|c|c|c|c|}
\hline \multirow{2}{*}{\multicolumn{2}{|c|}{$\begin{array}{c}\text { Sampling } \\
\text { Frequency } \\
\text { Months/ week }\end{array}$}} & \multicolumn{5}{|c|}{$\begin{array}{c}\text { Daphnia Toxicity } \\
\text { (Gd) }\end{array}$} & \multicolumn{5}{|c|}{$\begin{array}{l}\text { COD } \\
(\mathrm{mg} / \mathrm{l})\end{array}$} & \multicolumn{5}{|c|}{$\begin{array}{c}\text { Suspended Solids } \\
\text { (mg/l) }\end{array}$} \\
\hline & & I & $\mathbf{P}$ & $\mathbf{S}$ & $\mathbf{E}$ & $\%$ & I & $\mathbf{P}$ & $\mathbf{S}$ & $\mathbf{E}$ & $\%$ & $\mathbf{I}$ & $\mathbf{P}$ & $\mathbf{S}$ & $\mathbf{E}$ & $\%$ \\
\hline \multirow[t]{3}{*}{ Dec } & I & 16 & 12 & 4 & 1 & 100 & 335 & 296 & 180 & 120 & 64.2 & 134 & 132 & 104 & 24 & 82.1 \\
\hline & II & 16 & 12 & 4 & 1 & 100 & 368 & 256 & 136 & 128 & 65.2 & 142 & 134 & 110 & 24 & 83.1 \\
\hline & III & 16 & 12 & 4 & 1 & 100 & 396 & 292 & 188 & 140 & 64.7 & 160 & 142 & 98 & 30 & 81.3 \\
\hline \multirow[t]{3}{*}{ Jan } & I & 16 & 8 & 3 & 1 & 100 & 366 & 280 & 168 & 130 & 64.5 & 145 & 136 & 104 & 26 & 82.1 \\
\hline & II & 16 & 12 & 4 & 1 & 100 & 350 & 220 & 140 & 124 & 64.5 & 154 & 145 & 110 & 18 & 88.3 \\
\hline & III & 16 & 12 & 4 & 1 & 100 & 325 & 236 & 144 & 110 & 66.2 & 148 & 129 & 88 & 12 & 91.9 \\
\hline \multirow[t]{3}{*}{ Feb } & I & 16 & 12 & 4 & 1 & 100 & 342 & 215 & 130 & 110 & 67.8 & 160 & 138 & 106 & 22 & 86.3 \\
\hline & II & 16 & 12 & 4 & 1 & 100 & 330 & 260 & 172 & 128 & 61.2 & 188 & 172 & 135 & 32 & 83.0 \\
\hline & III & 16 & 12 & 4 & 1 & 100 & 385 & 294 & 190 & 130 & 66.2 & 176 & 166 & 122 & 48 & 72.7 \\
\hline \multirow[t]{3}{*}{ March } & I & 16 & 8 & 4 & 1 & 100 & 360 & 244 & 164 & 138 & 61.7 & 187 & 166 & 114 & 25 & 86.6 \\
\hline & II & 16 & 12 & 3 & 1 & 100 & 310 & 234 & 158 & 120 & 61.3 & 150 & 134 & 92 & 18 & 88.0 \\
\hline & III & 16 & 12 & 4 & 1 & 100 & 315 & 220 & 124 & 108 & 65.7 & 177 & 162 & 134 & 28 & 84.2 \\
\hline
\end{tabular}

I: Influent or Raw wastewater; P: After primary settling tank; S: After secondary settling tank; E: Effluent or After tertiary Treatment; $\%$ : Percentage removal 


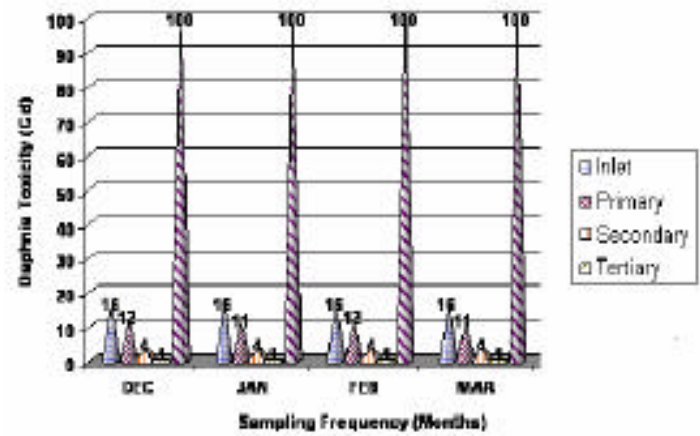

Fig.1. Status of Daphnia toxicity (Gd) at different treatment level of CETP.

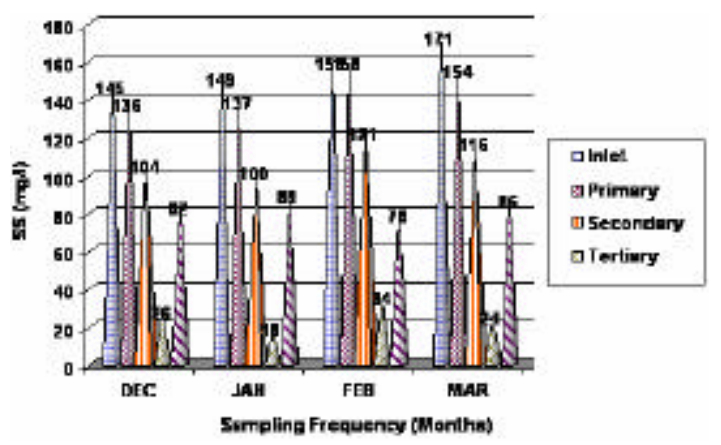

Fig. 3. Status of Suspended Solids (SS) at different treatment level of CETP.

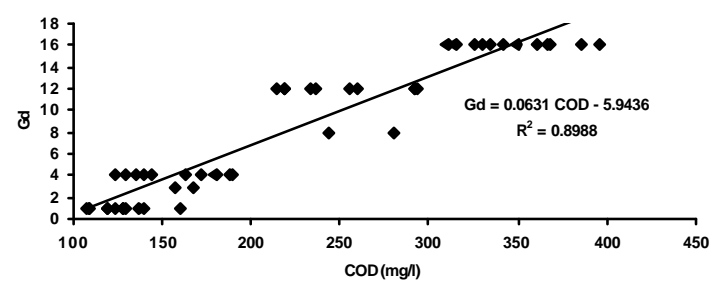

Fig. 5. Interrelationship between Daphnia toxicity (Gd) and chemical oxygen demand.

$\mathrm{Gd}=0.0978 \mathrm{SS}-2.4465\left(\mathrm{r}^{2}=0.801\right)$.

The statistical analysis of data revealed that Daphnia toxicity $(\mathrm{Gd})$ exhibit a good coefficient of correlation with COD $\left(r^{2}=0.899\right)$ and SS $\left(r^{2}=0.801\right)$ (fig. $\left.5 \& 6\right)$. It shows that Gd value could be more strongly correlated to COD than SS.

The observations revealed that an efficient final clarification step, which eliminates COD and SS in wastewater, plays a central role in toxicity reduction in

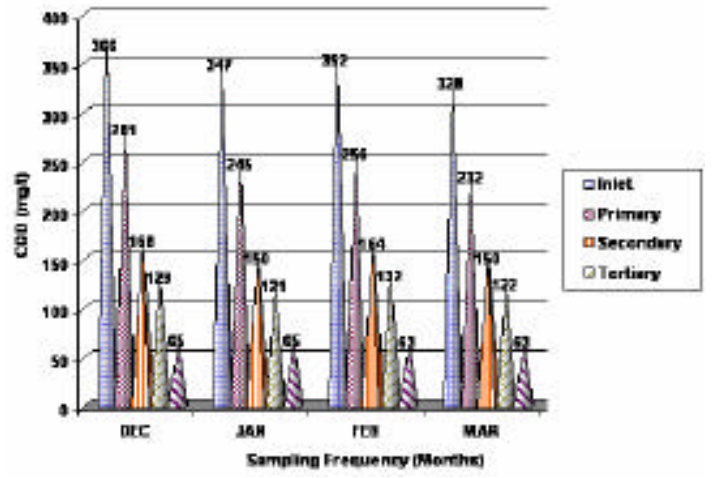

Fig.2. Status of Chemical Oxygen Demand (COD) at different treatment level of CETP.

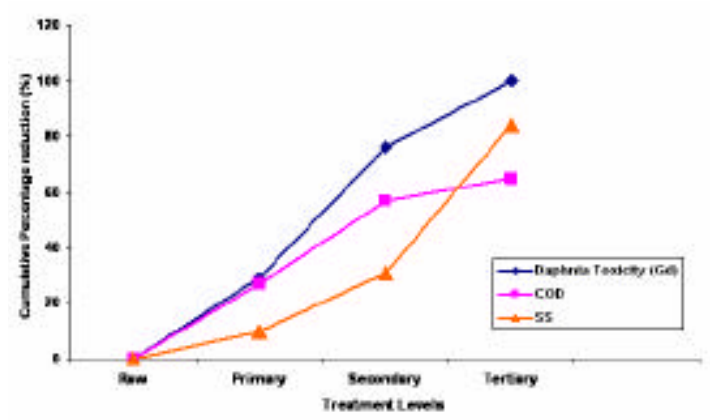

Fig. 4. Cumulative reduction of performance parameters at different treatment levels of CETP.

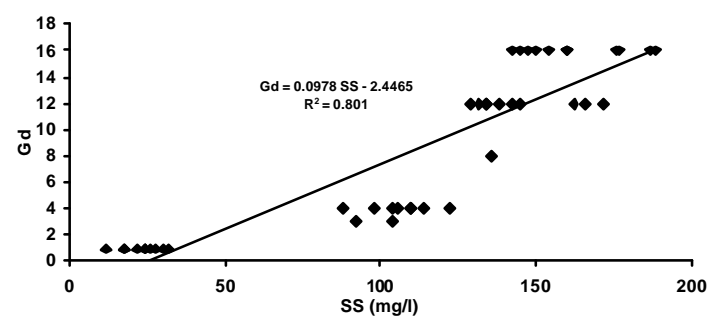

Fig. 6. Interrelationship between Daphnia toxicity $(\mathrm{Gd})$ and suspended solids.

conventional wastewater treatment system. Therefore, for up gradation of sewage treatment plant in terms of toxicological quality, the effluent suspended solids and chemical oxygen demand should be as low as possible by providing optimal treatment and settling conditions to the aeration and sedimentation tanks. Moreover our results indicate that toxicological pollution to receiving natural waters was not strongly dependent on influent water quality or seasonal variations instead, it was related 
to the efficiency of treatment processes in removing organic loads i.e. COD and SS. Our observations are in concomitant with the findings of Hernando et al., (2004). According to Hernando et al., (2004) the use of biological assay can provide a direct and appropriate measure of toxicity to complement the physico- chemical measures of the quality of wastewater.

Finally the authors believe that more discussion should be undertaken regarding the efficacy of process requirements versus toxicological quality goal of secondary or tertiary treated water.

\section{Conclusion}

The following conclusion can be put forward from this study: (i) This test can be considered as useful analytical tools for screening of chemical analysis and early warning system to monitor the different operational units of wastewater treatment plants, (ii) Interrelationship between COD, SS with respect to Daphnia toxicity (Gd) suggests that improvements of the toxicological quality of wastewater could be linked to the removal of both COD and suspended solids. Both the parameters (COD \& SS) can serve as a regulatory tool in lieu of an explicit toxicological standard, (iii) The toxicity testing could be help to reduce influenttoxicity and thereby avoid impacting microorganism's population in activated sludge systems and (iv) The bioassay method is indispensable and complimentary and support the earlier view that Daphnia magna can serve as a valuable model for bio- monitoring of water pollution and for evaluation of the toxicity of an effluent and risk assessment in an aquatic body, as it is highly sensitive to pollutants.

\section{ACKNOWLEDGEMENT}

The author is thankful to the authorities of Central Pollution Control Board (CPCB), Delhi for providing facilities, guidance and continuous encouragement during the course of project.

\section{REFERENCES}

APHA, AWWA, WEF (1998). Standards methods for the examination of water and wastewater, 20th edition, American Public Health Association, American Water Works Association and Water Environmental Federation, Washington, DC 200052605.

Blinova, I. (2000). Use of bioassays for toxicity assessment of polluted water. Proceedings of the symposium dedicated to the $40^{\text {th }}$ anniversary of environmental engineering at Tallinn Technical University. 24- 26 September, Tallinn, Tallinn, 149154.

Council Directive 91/ 271/ EC of 21 May (1991). concerning urban wastewater treatment, official Journal of European Communities.

German Standard Methods, (L-30), DIH-38412, Part 30, (1989). Examination of Water, Wastewater and Sludge, Bio-assays (Group L) Determining Tolerance of Daphnia to Toxicity of Wastewater by way of a Dilution Series, March 1989.

Hernando, M.D., Fernandez- Alba, A.R., Tauler, R. and Barcelo, D (2004) Toxicity assays applied to wastewater treatment, Talanta 65: 358- 366.

Turk, J. and Turk, A. (1984) Environmental Science, $3{ }^{\text {th }}$ edition, Saunders College Publishing, USA.

Verma, Y., Ruparelia, S.G. Hargan, M.C and Kulkarni, P.K (2003). Toxicity testing of the effluents from dye industries using daphnia bioassay, Journal of Indian Association for Environmental Management, 30:74- 76.

Villegas- Navarro, A., Romero Gonzalez, M.C. and Rosas Lopez, E. (1999). Evaluation of daphnia magna as an indicator of toxicity and treatment efficacy of textile wastewater, Environmental International, 25 (5) : 619-624. 